\title{
Insight into the changing patterns in clinical and academic activities of the orthopedic residents during COVID-19 pandemic: a cross-sectional survey
}

\author{
Sitanshu Barik ${ }^{1}\left[\right.$. Souvik Paul ${ }^{1}\left[\right.$. Pankaj Kandwal ${ }^{1}[0$ \\ Received: 16 July 2020 / Accepted: 7 September 2020 / Published online: 14 September 2020 \\ (c) European Society of Sports Traumatology, Knee Surgery, Arthroscopy (ESSKA) 2020
}

\begin{abstract}
Purpose The COVID-19 pandemic has presented an unprecedented challenge to the orthopedic residency training programs to adapt to a form of a web-based learning process and simulation-based training. This study focusses on the viewpoint of the orthopedic residents to the paradigm shift in clinical care as well as the academic activities.

Methods An anonymous questionnaire was created in an online survey generator and was sent through e-mail to 227 orthopedic residents of seven tertiary care centres in North India. The questionnaire was divided into three sections, academic activity section, mental health section, and clinical activity section. There were a total of 44 single answer questions with answers according to the increasing difficulty at present situation compared to a previous time before the COVID-19 pandemic.

Results A total of 158 questionnaires were filled by 107 junior residents (67.7\%) and 51 senior residents (32.3\%). 49 residents $(31 \%)$ were quarantined and three became positive for COVID-19. Although all of them knew about necessary precautions, personal protective equipment was difficult to avail at times. Increased difficulty in recruiting new patients for research (48.9\%) and conducting prospective research (48.7\%) was observed. The online-based learning process was reported to be easier (44.2\%) by most of the residents. Routine clinical work in the operating room, out-patient department, and inpatient department was found to be difficult according to the majority of the residents along with the anxiety of contracting the infection.

Conclusion There are unique opportunities for improvement of residency programs during these times of uncertainty and the findings of this study can help the universities as well as program chairs to develop a robust program that can outlive this pandemic. The web-based learning process might prove to be useful and can be incorporated into the resident training program in the long term.
\end{abstract}

Level of evidence Level V.

Keywords COVID-19 $\cdot$ Orthopedics $\cdot$ Personal protective equipment $\cdot$ Residency $\cdot$ Mental health

Souvik Paul

1990.souvik@gmail.com

Sitanshu Barik

sitanshubarik@gmail.com

Pankaj Kandwal

pankajkandwal27@gmail.com

1 Department of Orthopaedics, All India Institute of Medical Sciences, Rishikesh, India

\section{Introduction}

The COVID-19 (coronavirus disease 2019) global pandemic has emerged to be the biggest threat faced by the healthcare system of India at present. Since the first case reported in Kerala, the epidemic has rippled through the whole country within a matter of days $[17,18]$. While facing a crisis of healthcare workers, all elective surgeries had been cancelled in most of the hospitals in India since April 2020 [3]. Like other specialties, orthopedic residents have been frontline soldiers in this battle against coronavirus pandemic since the beginning $[4,5]$. Looking at the drastically falling numbers of elective orthopedic surgeries $[4,5,11,16]$, residents have been posted in COVID-19 screening out-patient 
departments, intensive care departments, inpatient departments, and telemedicine centre at different centres around the world $[12,13]$. They have been utilized by dividing into teams, where one team will be appointed to serve COVID-19 patients, whereas other teams will be posted in orthopedic duties or kept in quarantine [9]. There has been a paradigm shift in the learning process of residents from problem-based learning to the virtual web-based learning process [7]. There has been an upsurge of webinars and educational meetings conducted on different web platforms [7]. Teams of orthopedic residents have been quarantined routinely or after being exposed to some COVID-19-positive patients. Some of the orthopedic residents have also appeared for different forms of examinations too during this period including end-term examination for junior residency.

The current body of literature lacks specific studies focussing on the resident's feedback on these drastic changes in the routine clinical and academic activities. The resident's perspective can help to improve the curriculum of orthopedic residency program all over the world according to the present pandemic situation. This study aims to highlight the experience of orthopedic residents while working in current situations in orthopedic as well as non-orthopedic duties. It also aims to bring the mental status of the residents into the spotlight, while they cope with this stressful work environment which has not been explored before.

\section{Materials and methods}

The study was done in accordance with the ethical standards of our institution (AIIMS/IEC/20/174). An online survey was conducted by emailing 227 anonymous questionnaire to orthopedic residents of seven tertiary care centres in North India. Among them, 158 filled questionnaires were received (78.4\%). The questionnaire was divided into three sections, namely, the academic activity section, the mental health section, and the clinical activity section (see Figs. 1,2). The academic activity section was divided into three subsections-online academic activities, research, and examination section. Most of the residents underwent summative assessments in between this period in different centres. The cognitive domain was assessed by multiple-choice questions. Whereas the affective and psychomotor domains were evaluated by objective structured clinical/practical examination (OSCE/OSPE) and case scenarios using standardized patient. The respective sections were designed to get to know the perspective of the residents on the change of curriculum and clinical works. All participants were also required to answer general questions about their age, current affiliation, the experience of treating COVID-19 positive patients, awareness about precautions while working in COVID-19 designated area including steps of donning and doffing personal protective equipment (PPE), history of quarantine, or taking COVID-19 tests and if anyone tested positive for the infection. All participants were asked to provide a single answer for all the questions if possible and skip the questions which they did not find suitable to answer. The questions had the same options for answers according to the increasing difficulty at present compared to a previous time before the COVID-19 pandemic. All junior or senior orthopedic residents working in the present situations were included in the study. A pilot study was conducted in ten residents fulfilling the inclusion criteria for testing comprehensibility, ease of reading, and acceptability of questionnaires. Each question was assessed for suitability on a Likert scale of 1-5 (1: suitable to 5 highly suitable). Missing responses for each question were also assessed. Data from the pilot study were not included in the main study. The aim of the study was to assess the maximum percentage of responses for each questions denoting the degree of difficulty of that work at the present time.

The questionnaire was created in an online survey generator and the collected data were transferred to excel sheets (Microsoft excel 2016) for further analysis. The percentage of response for each answer in all of the 44 questions were noted. All quantitative variables were expressed in terms of mean and standard deviation. The statistical analysis was done in IBM SPSS version 26.0.

\section{Results}

The mean age of participants was $29.7 \pm 4.3$ years. There were 107 junior residents $(67.7 \%)$ and 51 senior residents (32.3\%). All of the residents had been posted in COVID19 patient care areas and were aware of all the precautions for COVID-19 patient care including steps of donning and doffing PPE. However, 49 residents $(31 \%)$ were quarantined due to contact with a COVID-19-positive patient. A total of 57 residents had undergone COVID-19 testing due to various reasons and three residents among them tested positive. The questionnaire was completely filled by 133 residents $(84.2 \%)$, whereas the examination-related questions in the academic activity section were not attempted by 19 residents $(12.02 \%)$, and 8 residents $(5.06 \%)$ left research questions incomplete. In the pilot study, all of the questions were answered by most of the participants $(97.27 \%)$. The mean score according to the Likert scale was $3.85 \pm 0.5$.

\section{Academic activity section}

Most of the residents found overall learning through web platforms $(44.2 \%)$ to be easier than before. However, the majority of residents felt that participating in an online case presentation $(55.3 \%)$ and maintaining the attention of the 
Fig. 1 Figure showing questionnaire (academic activity section and mental health section)

\section{Effect of COVID-19 on Resident training program}

Please put single answer for each question. Leave the questions that doesn't applicable to your experience. Comparison is to be done with academics or clinical activity before and after COVID-19 affection.

Your current affiliation and designation?

What is your age?

Have you been treating COVID positive patient? Yes/No

Are you aware of all precautions while working in a COVID area? Yes/No

Have you been quarantined? Yes/No

Have you taken any COVID test? Yes/No, If yes how many? ........

Have you been tested positive? Yes/No

\begin{tabular}{|c|c|c|c|c|c|}
\hline & Very difficult & Difficult & Same & Easy & Very easy \\
\hline Academic activity section & & & & & \\
\hline 1. Examination & & & & & \\
\hline Interaction with examiners & & & & & \\
\hline $\begin{array}{l}\text { Interaction with standardized } \\
\text { patients (dummy) }\end{array}$ & & & & & \\
\hline Online interface-based viva voce & & & & & \\
\hline Environment of exam & & & & & \\
\hline $\begin{array}{l}\text { "Multiple choice question" pattern of } \\
\text { the Theory exam }\end{array}$ & & & & & \\
\hline Complete OSCE/OSPE pattern & & & & & \\
\hline 2. Research & & & & & \\
\hline Recruiting new patients for research & & & & & \\
\hline Conducting a prospective research & & & & & \\
\hline $\begin{array}{l}\text { Conducting retrospective research with } \\
\text { available data }\end{array}$ & & & & & \\
\hline Getting time for research & & & & & \\
\hline Getting research published & & & & & \\
\hline 3. Online academic activities & & & & & \\
\hline Managing time to study & & & & & \\
\hline Preparing for an academic activity(slides) & & & & & \\
\hline Interaction with audience & & & & & \\
\hline Maintain the attention span of the audienc & & & & & \\
\hline Any gain in knowledge for a presenter & & & & & \\
\hline Technicality of an online conference & & & & & \\
\hline Quality of Case scenario/case presentation & & & & & \\
\hline Overall learning through web platforms & & & & & \\
\hline * Mental health section & & & & & \\
\hline Spending time during isolation/quarantine & & & & & \\
\hline Pursuing non-orthopaedic hospital duties & & & & & \\
\hline Managing time for yourself & & & & & \\
\hline Socializing with others & & & & & \\
\hline
\end{tabular}

audience (63.8\%) during any online presentation were relatively difficult than offline activities.

During the present situation, recruiting new patients (48.9\%) and conducting prospective research $(48.7 \%)$ posed difficulty to most of the residents. Although there were difficulties in facing a complete online interface-based viva voce $(45.8 \%)$, multiple-choice questions (MCQ) or Objective Structured Clinical and practical examination (OSCE/
OSPE) di not pose any problem for most of the residents (47.8\% and $45.6 \%$ respectively). The responses are summarized in Table 1.

\section{Mental health section}

The majority of residents found spending time during quarantine (40.4\%), pursuing non-orthopedic hospital duties (59.5\%), 
Fig. 2 Figure showing questionnaire (clinical activity section)

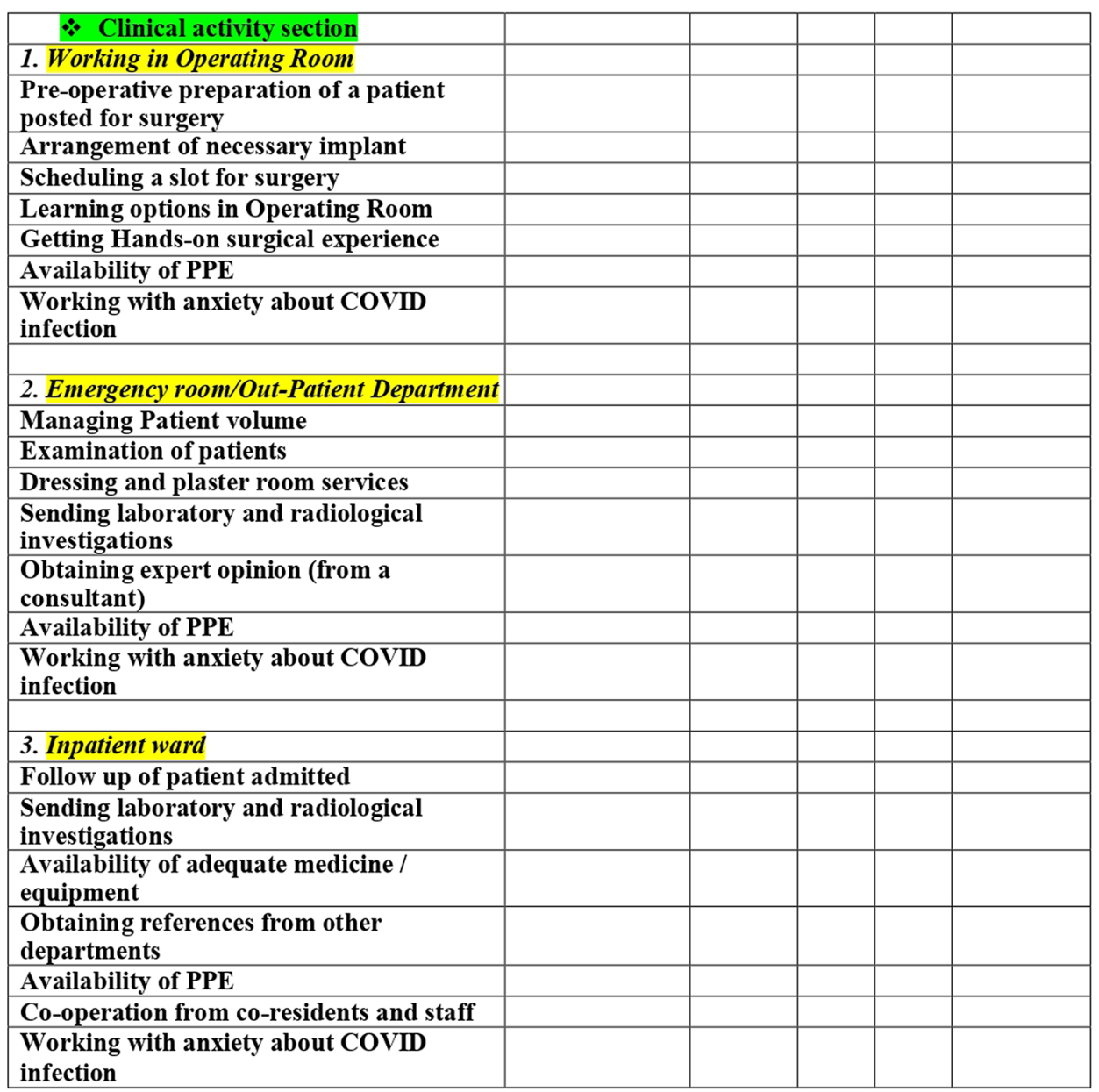

and socializing with others $(48.9 \%)$ to be difficult in the current situations.

\section{Clinical activity section}

PPE was difficult to obtain in operating room (OR) (46.8\%), out-patient department (OPD) (38.3\%), and inpatient department (IPD) (38.3\%). Among clinical activities, working in OR was found to be difficult in all aspects. It was also noticed that the clinical examination of patients (68.1\%), working at dressing and plaster room (53.2\%), and sending laboratory or radiological investigations in OPD (55.3\%) are to be difficult than before. The majority of the residents $(51.3 \%, 53.2 \%$, and $56.3 \%$ in IPD, OR, and OPD, respectively) were found to be working with anxiety about contracting COVID-19 infection.

\section{Discussion}

The most important findings of the present study were that the orthopedic residents had been facing difficulties in performing routine OR, OPD, and IPD works during COVID-19 pandemic. The present situation has posed a threat to the mental health of residents by increased anxiety of contracting the disease and difficulty in spending time alone without socializing with others. Although residency training in orthopedics has been profoundly affected due to the present situation, it has been advocated for orthopedic surgeons to step up as role models in these times, both in clinical and medical education activities [2]. In the absence of little or no guidance, the administrators of residency programs had to develop methods and strategies to keep imparting quality as well as feasible clinical care as well as medical education in these times. However, the literature lacks the feedback of orthopedic residents to these changes and whether they can be carried out in the long term. This study, one of the first in the literature, focusses on the viewpoint and feedback of the orthopedic residents to the paradigm shift in clinical care as well as the academic activities.

Crises like this are an opportune moment for educators to potentially alter the mode of resident training. The medical education in these times has transitioned into a more digital format with an increased amount of seminars and didactic lectures being conducted online with the help of video 
Table 1 Percentages of responses to all questions

Very difficult Difficult $\quad$ Same $\quad$ Easy Very easy

Academic activity section

1. Examination

Interaction with examiners

Interaction with standardized patients (dummy)

Online interface-based viva voce

Environment of exam

"MCQ" pattern of the theory exam

Complete OSCE/OSPE pattern

2. Research

Recruiting new patients for research

Conducting a prospective research

Conducting retrospective research with available data

Getting time for research

Getting research published

3. Online academic activities

Managing time to study

Preparing for an academic activity (slides)

Interaction with audience

Maintain the attention span of the audience

Any gain in knowledge for a presenter

Technicality of an online conference

Participating in a case scenario/case presentation

Overall learning through web platforms

Mental health section

Spending time during isolation/quarantine

Pursuing non-orthopedic hospital duties

Managing time for yourself

Socializing with others

\section{Clinical activity section}

\section{Working in operating room}

Pre-operative preparation of a patient posted for surgery

Arrangement of necessary implant

Scheduling a slot for surgery

Learning options in Operating Room

Getting Hands-on surgical experience

Availability of PPE

Working with anxiety about COVID-19 infection

2. Emergency room/out-patient department

Managing patient volume

Clinical examination of patients

Dressing and plaster room services

Sending laboratory and radiological investigations

Obtaining expert opinion (from a consultant)

Availability of PPE

Working with anxiety about COVID-19 infection

\section{Inpatient ward}

Follow up of patient admitted

Sending laboratory and radiological investigations

Availability of adequate medicine / equipment

Obtaining references from other departments

Availability of PPE

Co-operation from co-residents and staff

Working with anxiety about COVID-19 infection
2.4

2.4

2.4

4.3

8.7

38.3

48.7

25.5

2.1

17

4.3

2.1

4

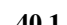

53.3

35.9

$\begin{array}{lll}24.8 & 17.1 & 2.4\end{array}$

$19.1 \quad 2.4$

$\begin{array}{lllll}45.8 & 34.8 & 14.6 & 2.4\end{array}$

$\begin{array}{llll}27.2 & 31 & \mathbf{3 5 . 3} & 2.2\end{array}$

$\begin{array}{lllll}34.7 & 47.8 & 6.5 & 2.2\end{array}$

$\begin{array}{llll}28.1 & 45.6 & 19.7 & 2.1\end{array}$

48.9

44.9

27.7

12.8

31.7

21.5

23.5

21.5

63.8

23.4

17.2

55.3

13.4

12

12.8

$6.4-\quad-$

$36.2 \quad 2.1 \quad 8.5$

$\begin{array}{lll}23.4 & 48.9 & 12.8\end{array}$

$\begin{array}{lll}38.6 & 10.6 & 2.1\end{array}$

$\begin{array}{lll}25.5 & 44.7 & 4.3\end{array}$

$\begin{array}{lll}25.5 & \mathbf{4 0 . 4} & 8.5\end{array}$

$18.9 \quad \mathbf{5 1 . 1} 4.3$

$23.4 \quad 4.3 \quad-$

$\begin{array}{lll}44.7 & 27.7 & 2.1\end{array}$

$40.2 \quad 36.2 \quad 6.4$

$\begin{array}{lll}38.3 & 2.1 & 2.2\end{array}$

$\begin{array}{lll}31.7 & 44.2 & 6.4\end{array}$

$40.4 \quad 10.6 \quad 27.7 \quad-$

$59.5 \quad 2.1 \quad 8.6 \quad-$

$\begin{array}{llll}28.3 & \mathbf{3 5 . 5} & 27.7 & 4.3\end{array}$

$\begin{array}{llll}48.9 & 17 & 6.4 & 4.3\end{array}$

21.7

52.2

61.7

51.1

40.4

44.8

46.8

53.2

21.7

$4.4-$

$\begin{array}{lll}19.1 & 2.2 \quad-\end{array}$

$\begin{array}{lll}14.9 & 12.8 \quad 2.1\end{array}$

$40.4 \quad 4.3$ -

$27.7 \quad 4.1 \quad-$

$21.3 \quad 25.5 \quad 2.1$

$19.1 \quad 4.2 \quad-$

21.3

$\begin{array}{lll}53.2 & 17 & 2.1\end{array}$

$68.1 \quad 14.9 \quad 2.1$ -

14.9

17

12.8

4.3

8.5

18.2

53.2

$23.4 \quad 4.3 \quad 2.1$

$\begin{array}{llll}55.3 & 29.8 & 2.1 & -\end{array}$

$\begin{array}{llll}38.3 & 51.1 & 6.4 & -\end{array}$

$\begin{array}{llll}38.3 & 27.7 & 19.1 & 6.4\end{array}$

$\begin{array}{llll}\mathbf{5 6 . 3} & 19.1 & 6.4 & -\end{array}$

4.3

63.8

$25.5 \quad 4.3 \quad 2.1$

$51.142 .6 \quad 4.1$ -

$\begin{array}{lll}38.5 & \mathbf{5 2 . 9} & 4.3\end{array}$

$63.5 \quad 21.3 \quad 6.4 \quad-$

$\begin{array}{llll}38.3 & 35.5 & 27.7 & -\end{array}$

$\begin{array}{llll}34 & 42.6 & 14.9 & -\end{array}$

$\begin{array}{llll}\mathbf{5 1 . 3} & 21.3 & 8.3 \quad-\end{array}$

COVID-19 2019 novel coronavirus, $M C Q$ multiple-choice questions, OSCE objective structured clinical examination, $O S P E$ objective structured practical examination, $P P E$ personal protective equipment 
conferencing and e-learning platforms [2, 15]. As overall learning through web platforms was found to be easy by the majority of residents in this study, online platforms can surpass the effectiveness of offline activities in future times. Similarly, instructional videos for procedural learning with faculty intervention for answering the questions of residents are a novel way forward. In the absence of broad guidelines from universities, it has been up to the program director to devise innovative ways to conduct medical education in consultation with the academic wing of the hospitals. Due to a sharp decrease in patients visiting hospitals with orthopedic complaints, residents had found it difficult to conduct a prospective research study during these times. Moreover, enrolling new patients or following them up might pose a threat to the patients and also to contract the disease while a visit to the hospital. The telephonic consultation and followup might be the way forward.

Many countries have started including OSCE/OSPE as the form of assessment for residents in their curriculum and use standardized patients for exams [6]. The literature lacks any conceptual framework for framing standardized OSCE/ OSPE questions [14]. Also, it is not clear whether the successful performance of OSCE/OSPE can be adjudged as having sound clinical judgement [8]. Although the majority of residents found it more difficult to get used to the onlinebased exam and its resultant difficulty in interaction with examiners as well as standardized patients, it has helped the final year residents to complete their junior residency within the stipulated time period.

The residents were demanded to bridge the gap in COVID-19 healthcare while managing emergency orthopedic cases during the pandemic. It was observed in this study that most of the work related to routine clinical activity has become more difficult during this pandemic. This finding may be attributed to the fact that many healthcare workers have been diverted from their routine services towards COVID-19 management [1]. The exception to this finding was noted in the ability to manage the patient volume, which was rated as easy owing to the reduced orthopedic cases during this period. Another factor that can be attributed to the same is that the residents were pooled into three teams. There was one team each for COVID-19 care and emergency orthopedic cases and the third team was placed on standby in case one of the above teams is quarantined for exposure. Despite the known highly contagious nature of the infection, a significant number of respondents had difficulty in obtaining PPE at their work stations (Table 1). This led to the increased anxiety regarding acquiring COVID-19 during their work routine as noted in this study. This anxiety has also got accentuated due to the frequent change of guidelines for the management and prevention of COVID-19.

It is still unknown how long will this pandemic last and for how long will the orthopedic residents be expected to care for non-orthopedic patients, which leads to a focus on the mental well-being of the residents [7]. The majority of residents in this study had apprehension regarding the quarantine/isolation and risk of infection during work. During these uncommon times of social distancing and less frequent face to face interaction, virtual social hours with the faculty and residents can be organised through online platforms to engage in topics apart from medical education. Efforts to reduce interpersonal isolation (increase interpersonal communication) help in minimising anxiety and stress that the residents are going through [10].

A major limitation of this study is that the findings are based on the responses of orthopedic residents from only one country, which may not be extrapolated to other countries all over the world. As other countries may have different types of health care system infrastructure and resident training programmes. Moreover, this study is also limited by the rapidly evolving strategies in public health as well as medical education, it has tried to provide a glimpse of the feedback from the orthopedic residents regarding early strategies employed after the cancellation of routine clinical and medical education services. It is difficult to quantify the efficacy of current strategies with respect to previous routine protocols.

As the fate of this pandemic is still unclear, some major changes need to be integrated into the residency training programmes all over the world. The findings of this study might enlighten the path in this decision -making. The emphasis must be put on web-based learning, simulation-based surgical process, and telemedicine-based patient consultations while providing the residents' maximum safety and mental support. Embracing these changes will lead the way to better patient care as well.

\section{Conclusion}

To conclude, this pandemic represents a challenge to program chairs to provide effective and feasible strategies for clinical care and medical education. There are unique opportunities for improvement of residency programs during these times of uncertainty and the findings of this study can help the universities as well as program chairs to develop a robust program that can outlive this pandemic. The webbased learning process might prove to be useful and can be incorporated into the resident training program in the long term. For all these strategies to succeed, the residents must feel protected and cared for. Embracing the feedback from the residents shall help the orthopedic education community to rise to the challenges of this pandemic.

Funding There is no funding source. 


\section{Compliance with ethical standards}

Conflict of interest The authors declare that they have no conflict of interest.

Ethical approval This study was approved by institutional review board.

Informed consent Informed consent was obtained from all individual participants included in the study.

\section{References}

1. An TW, Henry JK, Igboechi O, Wang P, Yerrapragada A, Lin CA, Paiement GD (2020) How are orthopaedic surgery residencies responding to the COVID-19 pandemic? An assessment of resident experiences in cities of major virus outbreak. J Am Acad Orthop Surg 28(15):e679-e685

2. Chang Liang Z, Wang W, Murphy D, Po Hui JH (2020) Novel Coronavirus and Orthopaedic Surgery: Early Experiences from Singapore. J Bone Joint Surg Am 102:745-749

3. COVID-19 IOA Guidelines (2020) Indian Orthopaedic Association, New Delhi2020. https://www.ioaindia.org/COVID-19IOA guidelines.pdf. Accessed 7 July 2020

4. Hirschmann MT, Hart A, Henckel J, Sadoghi P, Seil R, Mouton C (2020) COVID-19 coronavirus: recommended personal protective equipment for the orthopaedic and trauma surgeon. Knee Surg Sports Traumatol Arthrosc 28:1690-1698

5. Karasavvidis T, Hirschmann MT, Kort NP, Terzidis I, Totlis T (2020) Home-based management of knee osteoarthritis during COVID-19 pandemic: literature review and evidence-based recommendations. J Exp Orthop 7:52

6. Kirton SB, Kravitz L (2011) Objective structured clinical examinations (OSCEs) compared with traditional assessment methods. Am J Pharm Educ 75:111

7. Kogan M, Klein SE, Hannon CP, Nolte MT (2020) orthopaedic education during the COVID-19 pandemic. J Am Acad Orthop Surg 28:e456-e464

8. Kreiter CD, Bergus G (2009) The validity of performance-based measures of clinical reasoning and alternative approaches. Med Educ 43:320-325

9. Malhotra R, Gautam D, George J (2020) Orthopaedic resident management during the COVID-19 pandemic - AIIMS model. J Clin Orthop Trauma 11:S307-S308
10. Maunder R, Hunter J, Vincent L, Bennett J, Peladeau N, Leszcz M, Sadavoy J, Verhaeghe LM, Steinberg R, Mazzulli T (2003) The immediate psychological and occupational impact of the 2003 SARS outbreak in a teaching hospital. CMAJ 168:1245-1251

11. Mouton C, Hirschmann MT, Ollivier M, Seil R, Menetrey J (2020) COVID-19 - ESSKA guidelines and recommendations for resuming elective surgery. J Exp Orthop 7:28

12. Rahman OF, Murray DP, Zbeda RM, Volpi AD, Mo AZ, Wessling NA, Mina BA, Mendez-Zfass MS, Carpati CM (2020) Repurposing Orthopaedic Residents Amid COVID-19. JBJS Open Access 5:e0058-e0058

13. Sarpong NO, Forrester LA, Levine WN (2020) What's Important: Redeployment of the Orthopaedic Surgeon During the COVID-19 Pandemic: Perspectives from the Trenches. J Bone Joint Surg Am 102(12):1019-1021

14. Stansfield RB, Diponio L, Craig C, Zeller J, Chadd E, Miller J, Monrad S (2016) Assessing musculoskeletal examination skills and diagnostic reasoning of 4th year medical students using a novel objective structured clinical exam. BMC Med Educ 16:268

15. Stella JJ, Lamb DL, Stain SC, Termuhlen PM (2018) Understanding ACGME Scholarly Activity Requirements for General Surgery Programs in the Era of Single Accreditation and the Next Accreditation System. Am Surg 84:40-43

16. Thaler M, Khosravi I, Hirschmann MT, Kort NP, Zagra L, Epinette JA, Liebensteiner MC (2020) Disruption of joint arthroplasty services in Europe during the COVID-19 pandemic: an online survey within the European Hip Society (EHS) and the European Knee Associates (EKA). Knee Surg Sports Traumatol Arthrosc 28:1712-1719

17. The Lancet (2020) India under COVID-19 lockdown. The Lancet 395(10233):1315. https://www.thelancet.com/journals/lance t/article/PIIS0140-6736(20)30938-7/fulltext\#articleInformation. Accessed 7 July 2020

18. Ward A (2020) India's coronavirus lockdown and looming crisis, explained - Vox. https://www.vox.com/2020/3/24/21190868/coron avirus-india-modi-lockdown-kashmir. Accessed 7 July 2020

Publisher's Note Springer Nature remains neutral with regard to jurisdictional claims in published maps and institutional affiliations. 